\title{
Overuse of Cigarettes Smoking and Link with Urologic Disease
}

\author{
Kim Drasa Jr. ${ }^{1}$, Evin Dani ${ }^{2}$ \\ Central Polyclinic, Tirana, Albania
}

\begin{abstract}
Tobacco smoking is a major worldwide cause of morbidity and mortality from various diseases, including urologic diseases. Cigarettes smoking is a leading cause of death from cancer, although the relationship between Smoking and urologic cancer is controversial. Objective: To evaluate the available evidence of the role of the cigarette smoking and urologic disease development and progression, and to discuss possible clinical implication for Urologic Disease management. Material \& Methods: A literature search was conducted to identify original articles, reviews, editorials, and international scientific congress abstracts(published in English language) combining the following terms: cigarette smoking, urogenital diseases, smokeless tobacco, tobacco cessation We selected articles according to predefined inclusion criteria and the Preferred Reporting Item for Systematic reviews and Meta-analysis. Results: Most of the studies demonstrated the link between Cigarette smoking and Urologic diseases. The association between cigarette smoking and Urologic diseases incidence is controversial, particularly in recent series. Current cigarette smoking is associated with an increased risk of Urologic diseases morbidity, and the number of cigarettes smoked per day a dose-response association with Urologic diseases mortality. Smokers present a high risk of biochemical or distant failure after urologic diseases treatment. Several biological mechanisms behind these association have been proposed, although the molecular mechanisms remain unclear. Further research is required to better understand the role of smoking of urologic cancer developing and progression and, particularly to evaluate the possible effect of smoking cessation on urologic malignant/non-malignant diseases management. Conclusion: Data from the PeerReviewed literature suggested an association of smoking and aggressive urologic cancer. Although the pathophysiology underling these association remains unclear. Smokers presented higher urologic cancer mortality and worse outcome after treatment. Smokingcessation counseling should be implemented for patient with urologic malignant/non-malignant diseases, although its effect on urologic cancer progression should be investigated.
\end{abstract}

Keywords: Cigarettes, smoking, Cancer

\section{Patient Summary}

We looked at the association between smoking and Urologic Cancer mortality and worse outcomes after treatment. Smoking cessation should be encouraged in men with or at risk of having Urologic malignant/non-malignant diseases.

Tobacco use is a major preventable cause of premature death and disease worldwide. Smoking is the best established individually, amenable risk factor for the development of $>18$ types of cancer and the cause of death from many nonmalignant diseases. A robust body of evidence today documents the health consequences both from active smoking and exposure to second-hand smoke across a range of diseases and organ systems, especially cancers. There is strong evidence that tobacco has the potential to harm nearly every human organ. Approximately 5.4 million people die each year due to tobacco-related illnesses, a figure expected to increase to $>8$ million a year by 2030 . In the United States, the Centers for Disease Control and Prevention estimates that 443000 citizens die each year from smoking-related illnesses, and each day, thousands of teenagers try their first cigarette. In the enlarged European Union (EU25), smoking kills $>650000$ people every year, and the 13 million Europeans currently have tobacco-related chronic diseases.

If present patterns of use persist, tobacco use could cause as many as 1 billion premature deaths globally during the $21^{\text {st }}$ century. Male and female smokers lose an average of 13.2 and 14.5 years of life, respectively (1.2).
What can we as health care providers and researchers in urology do? We must counsel our patients regarding the detrimental effects of smoking because by not mentioning it we signal our acceptance. We also need to assist our patients in their attempts to stop smoking. Tobacco control has made a unique and substantial contribution to public health over the past half country. However, despite the success of tobacco control efforts in reducing premature deaths, smoking remains a significant public health problem. Although global estimated age-standardized prevalence of daily tobacco smoking declined by $25 \%$ for men and by $42 \%$ for woman between 1980 and 2012, substantial population growth over this period contributed to a $41 \%$ increase in the number of male daily smokers and $7 \%$ increase of female smokers. The number of cigarettes consumed worldwide increased by $26 \%$ during the same period, confirming that the global tobacco market continues to grow (3). In the United States, since the first Surgeon General Report on Smoking and Health (Issued on January 11, 1964) smoking rates have decreased by more than half (from $42.4 \%$ in 1965 to $18 \%$ today) and per capita consumption of cigarettes by $>70 \%$. This is not the case for Europe with some countries like Austria and Croatia even seeing a relative increase in the prevalence and rate of smoking. In Europe, variations in laws and behaviors have allowed somewhere between a third and a fifth of adults to continue smoking, and smoking continues to claim hundreds of thousands of lives annually. No other behavior comes close to contributing so heavily to the mortality burden of Western countries.

A potential factor that may offset the gains estimated in this study is the recent increase in use, particularly among young 


\section{International Journal of Science and Research (IJSR) \\ ISSN (Online): 2319-7064}

Index Copernicus Value (2013): 6.14 | Impact Factor (2014): 5.611

adults, of non-cigarette forms of tobacco such as smokeless tobacco, cigars, hookahs, and e-cigarettes. If these products are used instead of cigarettes, the adverse health effects are likely to be considerably less than that cigarettes. However, if used in combination with cigarettes these products may offset some of the potential benefits, especially as these young adults reach ages when smoking begins to claim its toll. Past successes of tobacco control have relied primarily on tax increases, media campaigns, laws regulating smoke-free air, and advertising bans.

\subsection{Overuse of Cigarettes Smoking and bladder Cancer}

Cigarette smoking is the number one environmental cause of bladder cancer (4).

Continuing to smoke is associated with worse diseaseassociated outcomes compared with those for patients who have discontinued their tobacco use(5). The risk of recurrent bladder cancer informer smokers decrease at a rate of up to $40 \%$ in the first 4 years after cessation (6).Continuing to smoke ,after the diagnosis of bladder cancer has been made, is associated with an increased risk of treatment -related complications, tumor recurrence, and the development of a second primary malignancy,(5) as well as of increased morbidity and mortality $(7,8)$.Data showed that bladder cancer was identified in 1430 of 154898 and 439 of 53173 patients, respectively(9). Although such numbers may argue against the use of screening, in men aged $>70 \mathrm{yr}$ with a smoking exposure $\geq 30$ pack -years (PYs), incidence rate were $>5$ per 1000 person -years, similar to the incidence of colon cancer detection of sigmoidoscopy (9). Men aged $>60$ yr with a smoking history $>30$ PYs had incidence rate $>2$ per 1000 person-years. Therefore the use of age and smoking history as selection criteria has the potential to identify population of sufficient risk to justify a screening strategy for bladder cancer. The highest bladder cancer mortality rates in men on year 2008 were in Poland, Spain, Latvia, and Lithuania ( $>7$ per 100000),followed by other eastern European counties and Denmark (6-7per 100000); the lowest ones were in Germany, Austria, Switzerland, Ireland and Finland $(<4$ per 100000). In woman the highest rates were in Denmark (2.3per 100000), Hungary, and United Kingdom (1.7per 100000); the lowest ones were in Russia, Finland, Ukraine and Belarus $(<0.8$ per 100000).

\subsection{Overuse of Cigarettes Smoking and Kidney Cancer}

Both the International Agency for Research Cancer and the US Surgeon General now consider cigarette smoking an established causal risk-factor for the development of renal cell cancer (10).A NIH review of the various environmental risk factors related to renal cell cancers concludes that the strongest of all associations is that between cigarette smoking and the development of kidney cancer- both of the renal parenchyma and of the renal pelvis and ureter. The relative risk has ranged in men from $27-37 \%$ and woman from $10-$ $24 \%$ (11). Smoking increases the risk for kidney cancer by $2-$ fold and $>4$-fold for bladder cancer $(12,13)$. The several known risk factors for kidney cancer are same as risk factors for bladder cancer that include smoking, age, and gender $(12,13)$
Moreover, the most cases controlled studies have demonstrated a dose-response relationship (14). The risk of developing renal cell cancer is increased for lifelong smokers who smoke more than 20 cigarettes per day (relative risk 2.1) compared with those who smoke $<10$ cigarettes per day (relative risk 1.1), and the risk appears to be high for smokers who started at an earlier age (15). Conversely, the risk seems to decline significantly by the number of years after cessation, leading to a $25-30 \%$ reduction in risk after $10-15$ years of cessation (14).

Similarly, urothelial cancers of the renal pelvis, like their downstream counterparts in the bladder, are associated with tobacco over use. Exposure to tobacco increase the relative risk of developing such upper tract cancer by a factor of 2.5 7.This risk, too, is amplified by the number of years of exposure and by the number of cigarette smoked. The risk decreases by about $60-70 \%$ after cessation for $>10$ years (16).The impact of cigarette smoking within the Native American population presents a unique conundrum. Tobacco over use is pandemic within this population, and the prevalence of kidney cancer is extraordinarily high (17). Yet the incidence of bladder cancer is inexplicably low(18). The highest mortality rates from kidney cancer in 2008 were in the Czech Republic ( 9 per 100.000 men and 3.7per 100.000 women) followed by Baltic countries (7-8 per 100.000 men and 2.5-2.7 per 100.000 women); the lowest ones were in Greece, Portugal and Luxembourg $(<3$ per 100000 men and $<1.2$ per 100.000 women).

\subsection{Overuse of Cigarettes Smoking and Prostate Cancer}

With the aging of the global population, Prostate cancer (PCa) has become one the most common malignancies among men in the European Community (19) with an estimated 180000 new cases diagnosed in the USA in 2000 alone(20). During the year 2014 more than 230000 American learned that they have PCa. While the $\mathrm{PCa}$ is rare before age 40, the risk grows with age. About 1 in 6 men in United States faces a diagnosis of $\mathrm{PCa}$ in his lifetime. African -American men and the men with family history with $\mathrm{PCa}$ are more likely to be diagnosed .One in 5 African-American men will be diagnosis with PCa in his lifetime. AfricanAmerican men are also twice as likely to be diagnosed with more deadly forms of the disease. About 1 in 3 men whose father or brother had PCa will be diagnosed. Their risk grows if two or more close relatives have been diagnosed, or if they were diagnosed before aged 55. PCa is associated with a high rate of microscopic disease; estimated that $32 \%$ of men aged 40-49 years and $64 \%$ aged 60-69 years had invasive PCa on autopsy. The association between cigarette smoking and $\mathrm{PCa}$ incidence is controversial, particularly in recent series. Current cigarette smoking is associated with an increased risk of PCa death, and the number of cigarettes smoking per day had a dose-response association with PCa mortality. Smokers present a high risk of biochemical of distant failure after PCa treatment. Several biological mechanism behind these association have been proposed although the molecular mechanism remain unclear. Further research is required to better understand the role of smoking on $\mathrm{PCa}$ development and progression and, particularly, to evaluate the possible effect of smoking cessation of PCa management. Data from 


\section{International Journal of Science and Research (IJSR) \\ ISSN (Online): 2319-7064}

Index Copernicus Value (2013): 6.14 | Impact Factor (2014): 5.611

peer-reviewed literature suggested an association of smoking and aggressive PCa. Although the pathophysiology underlying this association remains unclear, smokers presented higher PCa mortality and worse outcome after treatment. Smoking-cessation counselling should be implemented for patients with $\mathrm{PCa}$, although its effect on PCa progression should be investigated. Overall mortality rates from PCa have levelled off since the 1990s in most countries of western and northern Europe. In 2008 the highest mortality rate from PCa were in Baltic countries $(>20$ per $100000 \mathrm{men})$, followed by the Nordic countries. The lowest ones were in the Russian Federation and other central and eastern European countries as well as in Italy $(<10$ per 100000 men). More than 28000 men die each year from $\mathrm{PCa}$ in United States.

\subsection{Overuse of Cigarettes Smoking and Testicular Cancer}

With reference to testicular cancer the favourable trends observed in most European countries over the last decades are consistent with those observed in the United States $(21,22)$ although with a substantial delay, particularly in central/eastern Europe. Testicular cancer is one of the most curable neoplasm, the favourable pattern in mortality is largely attributed to the introduction (since1970s)of effective treatments, mainly platinum-derived chemotherapy.(21).As a consequence of improved treatment, survival from this neoplasm has increased through European countries over the last decades $(23,24)$. In contrast to mortality the incidence of testicular cancer has been increasing in most European countries in the last few decades (23). The delay in the reduction of mortality rates in countries from central/eastern Europe is mainly due to inadequate availability of treatments in those countries up to recent calendar years. The slowing down of the declines in testicular cancer mortality in countries of western and northern Europe over the most recent years suggests that mortality from this neoplasm is now reaching a plateau in these countries, as it has in the United States (21).

\subsection{Overuse of Cigarettes Smoking and Testicular Dysfunction}

Women who smoke during pregnancy increase the risk of cryptorchidism in their children. Perinatal exposure to cigarette smoke may irreversibly impair Sertoli cell proliferation in the child and subsequent spermatogenesis in the adult.

\subsection{Overuse of Cigarettes Smoking and Erectile Dysfunction}

A meta-analysis has founded that, although only of $20 \%$ of the general population smoked, $40 \%$ of men with erectile dysfunction (ED) were currently smokers (25). In a cohort from the Massachusetts Male Aging Study there was a greater incidence of moderate or severe ED among smokers than non-smokers (24\% vs $14 \%$, adjusted OR 1.97) (26). Men with a smoking history of 25 years had twice the risk (27). Even former smokers have been shown to have an increased risk (OR 2.2) of ED (28). It is possible that longterm overuse of cigarette smoking may lock-in irreversible damage not only to neuromuscular and vaso-endothelial mechanisms of penile erection, but also to neurovascular bodily functions system-wide. Considerable evidence exist to support the hypothesis/theory that smoking-related ED is mainly associated with endothelial impairment, reduction in nitric oxide availability, and imbalance between oxidative and antioxidative reactions increasing oxidative stress. Thus, the development of ED in a smoking patients may be a harbinger for this subsequent development of significant cardiovascular disease. Men who smoke and develop ED would benefit from through cardiovascular screening and follow-up. Passive second-hand cigarette smoking, especially with a long-term exposure, can also have a negative impact on erectile function. Smoking cessation may mitigate this effect and may help to restore lost function. The Health Professionals Follow-up Study showed that former smokers had a lower risk of ED that men who continue to smoke. However, they rate of ED was still higher than that for men who had never smoked (29).

\subsection{Overuse of Cigarettes Smoking and Infertility}

Cigarette smoking adversely affects reproductive function in both women and men. Our peer-review founded a significant decrease in all semen parameters among the men who smoke, particularly with respect to sperm motility. (30).Spermatozoa from smokers have reduced fertilizing capacity(30).Men who have been exposed to maternal tobacco components in utero may go on to have reduced sperm counts in adult life (31).In addition, an association has been suggested between smoking and testicular dysfunction with consequent infertility. A heightened risk of infertility in women have also been associated with smoking, caused by an increased incidence of tubal infertility, ectopic pregnancy, and pelvic inflammatory disease(32).Smoking also has a negative impact on the success of assisted reproductive technologies in women with infertility (28).

\subsection{Overuse of Cigarettes Smoking and Sexually Transmitted Diseases.}

Our review founded that, even after adjustment for possible confounding factors, smokers had an increased biological risk of acquiring HIV infection (33). Smoking has also been associated with an increased risk of acquiring human papillomavirus (HPV)-both high -and low - risk strains (34, 35). Smoking increase the risk of developing of invasive cervical cancer among women who harbour HPV 16 or 18 (33).Smoking has been identified as an independent risk factor for pelvic inflammatory disease in women (even after controlling for other risk taking behaviour),as well as for urethritis and chronic prostatitis/chronic pelvic pain syndrome in men $(33,36,37)$.

\section{Secondary Smoke Exposure}

The risk from secondary exposure to tobacco smoke -passive smoking -remain largely unexplored. However, at list 43 carcinogens and $>300$ polycyclic aromatic hydrocarbons, as well as many other known toxins, such as arsenic, carbon monoxide ,lead ,cyanide, dichlorodiphenyltrichloroethane 


\section{International Journal of Science and Research (IJSR) \\ ISSN (Online): 2319-7064}

Index Copernicus Value (2013): 6.14 | Impact Factor (2014): 5.611

(informally known as DDT), formaldehyde, and polonium210, have been identified among the 4000 chemical constituents of cigarette smoke (28)

\section{Smokeless Tobacco}

The use of smokeless tobacco, either as a cultural preference or as a smoking tobacco substitute, raises health care impact questions as well. Although in US, smokeless tobacco refers to moist snuff and chewing tobacco, this broad category comprises more than 30 different products worldwide (38). The safety of these smokeless products is subject to debate. Smokeless tobacco products are a major source of carcinogenic nitrosamines. In India and Sudan , $>50 \%$ of oral cancer attributable to smokeless tobacco products. Cancer risk for smokeless tobacco users is probably lower than that for smokers, but higher than that nonusers (39).Clinical correlations, although not conclusive, have been found between the use of smokeless tobacco products and development of prostate and kidney cancer (40)

\section{Discussion}

We see it as our obligation to raise the awareness that smoking remains a leading contributor to urologic health problems and premature death. Smoking is associated with the development and prognosis of prostate cancer, bladder cancer and renal cell carcinoma. In addition, smoking leads to erectile dysfunction, and, although there is heterogeneous evidence, it seems to be associated with lower urinary tract symptoms including benign prostate hyperplasia, chronic prostatitis, and chronic pelvic pain syndrome. It is evident that smokers today have much higher risk of developing urologic diseases than smokers in the 1960, probably because of changes in the design composition of cigarettes overtime.

We evidenced links of overuse cigarette smoking to several urological cancers, as well as to other genitourinary conditions. However, awareness of this inter-relationship seems to have had a very limited impact on clinical practice for most urologists.

For many patients, a cancer diagnosis represents a teachable moment to quit smoking successfully. In addition, urologic patients are willing to quit smoking with some education and help from their physicians. Physician interventions such as the five As (ask, advise, assess, assist, arrange) and the Ask Advice, and Connect method that encourage quitting and the use of effective cessation treatments can increase quit rates.

Most smokers wants to quit and many try on their own. However, their success rate without assistance is $<7 \%$ (41). Smoking cessation interventions that include both counseling and pharmacotherapy appear to be most effective (41). It must be recognized, however that there are significant barriers that currently dampen an urologist's enthusiasm for incorporating an effective behavioural counselling into routine practice. These impediments include an underestimate of the importance of prevention counselling, inadequate preparation in health promotion skills, lack confidence in their ability to modify their patients' habitual behaviors, and limited acceptance of responsibility for providing preventive counseling (42). There is growing support for urologists to have a more proactive role in promoting smoking cessation among their patients (43). However, a recent survey of American urologists showed that most urologists have reservations about incorporating cessation counseling into practice (44).

\section{Conclusion}

As urologists, we must accept the responsibility and better counsel our patients, about the detrimental effects of smoking and assist them in cessation efforts to improve their health and lives. Urologists are urged to share relevant information effectively with their patients and to exert influence in regard to adopting healthier lifestyles overall. Urologists are urged to recognize their responsibility for promoting awareness of tobacco toxicity not only among their patients, but also on a wider basis, within their communities at large and throughout the public sector. Too many of our patients have been maimed or have died prematurely from smoking. Tobacco use still remained the leading cause of preventable death in Europe. This is a winnable fight, and we need to be on the frontlines fighting for our patients against tobacco consumption. We need to eliminate the use of cigarettes and create a tobacco-free generation.

\section{References}

[1] Centers for Disease Control and Prevention (CDC).Annual smoking-attributable mortality, years of potential life lost,and economic costs-United States,1995-1999.MMWR Morb mortal wkly Rep 2002<51:300-3

[2] Doll R,Peto R, Boreham J, Sotherland I, Mortality in relation to smoking: 50 years' observations on male British doctors, BMJ 2004;328:1519.

[3] $\mathrm{Ng} \mathrm{M}$, Freeman MK, Fleming TD, et al. Smoking prevalence and cigarette consumption in 187 countries, 1980-2012.JAMA 2014; 311: 183-92.

[4] Hirao Y, Kim WJ, Fujimoto K. Environmental factors promoting bladder cancer. CurrOpin Urol. 2009; 19: 494-499.

[5] Fleshner N, Garland J, Moadel A, et al. Influence of smoking status on the disease-related outcomes of patients with tobacco-associated superficial transitional cell carcinoma of the bladder. Cancer. 1999; 86:23372345.

[6] Brennan P, Bogillot O, Cordier S, et al. Cigarette smoking and bladder cancer in men; a pooled analysis of 11 cases-control studies. Int J Cancer. 2000;86;289-294.

[7] Orleans C, Slade J. Treating nicotine addiction in highrisk groups and patients with medical co-morbidity. In: Orleans CT; Slade J, eds. Nicotine Addictions; Principles and Management. New York: Oxford University Press; 1993:279.

[8] RaitanenMP,Nieminen P, Tammela TL. Impact of tumour grade,stage,number and size, and smoking and sex, on survival in patients with transitional cell carcinoma of the bladder. Br J urol. 1995;76:470-474. 


\section{International Journal of Science and Research (IJSR) \\ ISSN (Online): 2319-7064}

Index Copernicus Value (2013): 6.14 | Impact Factor (2014): 5.611

[9] Krabble LM, Svatek RS, Shariat SF, Messing E, Lotan Y. Bladder cancer risk: use of the PLCO and NLST to identify a suitable screening cohort. UrolOncol. $<<<$ in press. DOI: 10. 1016/urolonc.2014.06.009.

[10] Chow WH, Dong LM, Devesa SS. Epidemiology and risk factors for kidney cancer. Nat. Rev Urol. 2010; 7:245-257.

[11] Moore LE, Wilson RT, Campleman SL. Lifestyle factors, exposures, genetic susceptibility, and renal cell cancer risk: a review. Cancer Invest. 2005;23:240-245.

[12] Navai N, Wood CG. Environmental and modifiable risk factors in renal cell carcinoma. UrolOncol 2012;30:2204.

[13] Burger M, Catto JW, Dalbagni G, et al. Epidemiology and risk factors of urothelial bladder cancer. EurUrol 20134;63:234-41.

[14] McLaughlin JK,Lipworth L. Epidemiologic asoects of renal cell cancer. SeminOncol. 2000;27:115-123.

[15] Fulgheroni P, Costa D, Sbarbati M, et al. Tobacco smoking and renal cell carcinoma. An overview. ContribNephrol. 2000; 130:134-135.

[16] Colin P, Koenig P, OuzzaneA,et al. Environmental factors involved in carcinogenesis of urothelial cell carcinoma of the upper urinary tract. BJU Int.2009; 104:1436-1330.

[17] Watson RA. Kidney Cancer in American Indian and native Alaskan men and women-time to notice, time to care. Urology. 2008; 72:726-730.

[18] Watson RA, Sidor M. Bladder cancer in Native Americans and Alaskan Natives. Urology. 2008; 72: 1014.

[19] Black RJ, Bray F, Parkin DM. Cancer incidence and mortality in the European Union. Cancer registry data and estimates of national incidence for 1990. Eur J Cancer 1997; 33: 1075-107.

[20]Ross PL, Scardino PT, Kattan MW. A catalog of prostate cancer nomograms. J Urol 2001; 165: 1562-8.

[21] Levi F,Lucchini F, Boyle P, Negri E, La Vecchia C. Testicular cancer mortality in Eastern Europe. Int $\mathrm{J}$ Cancer 2003; 105: 574.

[22] Bertuccio P, Malvezzi M, Chatenoud L, et al. Testicular cancer mortality in the Americas, 1980-2003. Cancer 2007; 109: 776-9.

[23] Karim -Kos HE, de Vries E, Soerjomataram I, Lemmens V, Siesling S, Coebergh JW. Recent trends of cancer in Europe : a combined approach of incidence, survival and mortality for 17 cancer sites since the 1990 s. Eur J Cancer 2008; 44: 1345-89.

[24] Condos A, Bray F, Hakulinen T, Brenner H. Trends in cancer survival in 11 European populations from 1990 to 2009: a model-based analysis. Ann Oncol 2009; 20: 564-73.

[25] Tengs TO, Osgood ND. The link between smoking and impotence: two decades of evidence. Prev Med. 2001; 32: 447-452.

[26] Feldman HA, Johannes CB, Derby CA et al: Erectile dysfunction and coronary risk factors: prospective results from the Massachusetts male aging study. Prev Med 2000; 30: 328.

[27] Polsky JY, Aronson KJ, Heaton JP, et al. Smoking and other lifestyle factors in relation to erectile dysfunction. BJU Int. 2005; 96: 1355-1359.
[28] Hruska KS, Furth PA, Seifer DB, et al. Environmental factors in infertility. ClinObstet Gynecol. 2000; 43: 821829.

[29]Bacon CG, Mittleman MA, Kawachil,et al. A prospective study of risk factors for erectile dysfunction. J Urol. 2006; 176: 217-221.

[30] Hussein A, Algadaa A AlFaras M, et al. Effect of tobacco smoking on semen quality in men with subfertility. UroTodayInt J. 2011; 4(1): doi: 10.3834/uij. 1944-5784. 2011.02.11

[31] Soares SR, Melo MA, Cigarette smoking and reproductive function. CurrOpinObstet Gynecol. 2008; 20: 281291.

[32] Scholes D, Daling JR, Stergachis AS. Current cigarette smoking and risk of acute pelvic inflammatory disease. Am J Public Health. 1992; 82: 1352-1355.

[33] Pittrof R, Goodburn E. Should we change the focus of health promotion in sexual health clinics? Sex Health. 2010; 7: 407-410.

[34]Kjaer SK, Tran TN, Sparen P, etal. The burden of genital wrts: a study of nearly 70.000 women from general female population in the 4 Nordic countries. J Infect Dis. 2007; 196: 1447-1454.

[35] Steben M, Duarte-Franco E. Human papillomavirus infection: epidemiology and pathophysiology. GynecolOncol. 2007; 107: S2-S5.

[36] Bartoletti R, Cai T, Mondaini N, et al. Prevalence, incidence estimation, risk factors and characterization of chronic prostatitis/chronic pelvic pain syndrome in urological hospital outpatients in Italy: results of a multicentre case-control observational study. J Urol. 2007; 178. 2411-2415; ( Discussion : 2415).

[37] Pessione F, Dolivo M, CasinI,et al. Sexual behavior and smoking: risk factors for urethritis in men. Sex Transm Dis. 1988; 15.119-122.

[38] Delnevo CD, Steinberg MB, Hudson SV, et al. Epidemiology of cigarette and smokeless tobacco use among South Asian Immigrants in the Northeastern United States. Oncology. 2011: 252675. Epub may 17, 2011.

[39] Boffeta P, Hecht S, Gray N, et al. Smokeless tobacco and cancer. Lancet Oncol. 2008; 9: 667-675.

[40]Lee PN, Hamling J. Systematic review of relation between smokeless tobacco and cancer in Europe and North America. BMC Med. 2009; 7:36. Available at: http://www.biomedcentral.com/1741-7015/7/36. Accessed August 2, 2011.

[41] Simon JA. Smoking cessation interventions: a primer for physicians: Comment on "Use of varenicline for 4 weeks before quitting smoking". Arch Intern Med.2011; 171: 777-778.

[42] Barzilai DA, Goodwin MA, Zyzanski SJ, et al. Does health habit counselling affect patient satisfaction? Prev Med. 2001; 33:595-599.

[43] Watson RA and Sadeghi-Nejad H: Tobacco abuse and urologist: time for a more proactive role. Urology 2011; 78:1219.

[44]Bjurlin MA, Goble SM and Hollowell CM: Smoking cessation assistance for patients with bladder cancer: a national survey of American urologists. J Urol 2010; 184:1901. 